\title{
Can a physician ever justifiably euthanize a severely disabled neonate?
}

Robert M. Sade, MD

See related articles on pages 533-4 and pages 535-7.

Physician-assisted suicide has been legalized in 3 states (Oregon and Washington by public referendum and Vermont by legislation) and has been judicially sanctioned in 2 others (Montana and New Mexico) ${ }^{1}$; it is illegal in the remaining 45 states. In assisted suicide, the assister is passively involved in causing death; in euthanasia, a person actively causes the death of another for the purpose of relieving pain and suffering. Euthanasia is illegal in all US states; to some, however, it seems only a matter of time before euthanasia is legalized, particularly in states where physician-assisted suicide has already been adopted.

Euthanasia is legally sanctioned in 3 European countries: The Netherlands, Belgium, and Luxembourg. In The Netherlands, a specific process guides selection of children younger than 12 years who could be candidates for euthanasia: the Groningen Protocol, developed in 2004, which is not a law, although public prosecutors deem it acceptable under certain guidelines. ${ }^{2,3}$ The Belgian Parliament recently modified its 2002 Act on Euthanasia to include not only adults but also children younger than 18 years. ${ }^{4}$

Assisted suicide and euthanasia have profound implications for the way we view the relationship among physicians, other professionals, health care, and death; the implications are especially serious for medical ethics. The Cardiothoracic Ethics Forum invited 2 outstanding philosophers to explore some of these issues; they are both wellknown for their scholarly positions in defense of opposing viewpoints regarding the acceptability of euthanasia. Their debate at the 94th Annual Meeting of The American Association for Thoracic Surgery focused on a hypothetical case involving euthanasia of a newborn infant.

From the Division of Cardiothoracic Surgery, Department of Surgery, Institute of $\mathrm{Hu}$ man Values in Health Care, Medical University of South Carolina, Charleston, SC. Supported by the South Carolina Clinical \& Translational Research Institute, Medical University of South Carolina's Clinical and Translational Science Award No. UL1RR029882.

Disclosures: Author has nothing to disclose with regard to commercial support.

Read at the 94th Annual Meeting of The American Association for Thoracic Surgery, Toronto, Ontario, Canada, April 26-30, 2014.

Received for publication Aug 28, 2014; accepted for publication Sept 15, 2014; available ahead of print Oct 11, 2014.

Address for reprints: Robert M. Sade, MD, Medical University of South Carolina, 25 Courtenay Drive, Suite 7028, MSC 295, Charleston, SC 29425-2270 (E-mail: sader@musc.edu).

J Thorac Cardiovasc Surg 2015;149:532

$0022-5223 / \$ 36.00$

Copyright (c) 2015 by The American Association for Thoracic Surgery

http://dx.doi.org/10.1016/j.jtcvs.2014.09.040

\section{THE CASE OF THE ILL-FATED NEONATE}

A full-term newborn infant is noted to turn blue while feeding a few hours after birth. Evaluation by a pediatric cardiologist reveals heterotaxy syndrome (polysplenia) with a group of extremely complex heart malformations that result in complete mixing of blood flow to the body and to the lungs. The cardiologist meets with the parents, explains the diagnosis, and outlines 4 alternative courses: surgical treatment, medical treatment, comfort care with feeding, and euthanasia.

Surgical treatment will require at least 3 risky heart operations before the age of 5 years. If these 3 or more operations were successful, the child might survive his teenage years. Additionally, the infant has impaired splenic function, which exposes him to increased threat of infections, and is at risk for intestinal obstruction, which would require 1 or more abdominal operations.

Medical therapy for heart failure without surgery would not reverse the infant's inevitably declining condition and at best would allow him to survive into early childhood.

With feeding and comfort care only, the baby would be expected to become progressively disabled and would most likely die within a year.

Euthanasia at this point would prevent future suffering. It is an option only because the state in which they reside has had a long-time policy allowing physician-assisted suicide and recently amended the law to allow euthanasia under circumstances such as this.

The parents consider this information and discuss it with other family members, close friends, and their spiritual advisor before making their decision. At the cardiologist's next visit, they tell him that if they had known about this problem, they would have terminated the pregnancy, because they do not wish their child to have a poor quality of life. Of the 4 available options, they believe euthanasia to be the most humane. Should the physician help them in this way?

\section{References}

1. Orentlicher D, Pope TM, Rich BA. The changing legal climate for physician aid in dying. JAMA. 2014;311:1961-2.

2. Verhagen E, Sauer PJ. The Groningen protocol—euthanasia in severely ill newborns. N Engl J Med. 2005;352:959-62.

3. Verhagen AA. The Groningen Protocol for newborn euthanasia; which way did the slippery slope tilt? J Med Ethics. 2013;39:293-5.

4. Siegel AM, Sisti DA, Caplan AL. Pediatric euthanasia in Belgium: disturbing developments. JAMA. 2014;311:1963-4. 